\title{
ЦИФРОВИЗАЦИЯ ГОСУДАРСТВЕННОГО УПРАВЛЕНИЯ В УСЛОВИЯХ ИННОВАЦИОННОГО РАЗВИТИЯ
}

Харченко В. А., Чернявская Т. Г. ГОУ ВПО «Донецкий национальный университет», г. Донецк

B cтатье определень основные направления циифровизации государственных услуг. Установлены предпосылки появления данного направления в современных условиях на основе сопоставления цииклов Кондратьева и развития экономики в мире. Выявлены ключевые сложности развития цчифрового государственного управления в Донецкой Народной Республике (ДНР, Республика); на основе российского опьта предложень мероприятия по их преодолению.

Ключевые слова: государственные услуги, электронное управление, цифровые технологии, цифровизация, электронные услуги, система «Электронное правительство», АИС «Обращения граждан»

Постановка проблемы. Интенсификация процесса информатизации современного общества предопределяет возникновение потребности в использовании новых возможностей, которые помогут обрабатывать больше данных за меньшие промежутки времени. Одним из путей решения этой проблемы может быть переход к оказанию государственных услуг с помощью информационно-коммуникативных технологий. Чрезвычайно важным является предоставление электронных государственных услуг, поскольку это позволит повысить результативность процессов предоставления и получения государственных услуг. Переход к предоставлению государственных услуг в электронном виде, безусловно, имеет свои препятствия, необходимость поиска путей по их преодолению обуславливает актуальность данного исследования.

Анализ последних исследований и публикаций. Вопросы использования цифровых технологий, развития цифровой экономики, инноваций в государственном управлении отражены в работах многих исследователей, таких как: И.А. Громов [2], К.Б. Костин [3], Л.А. Мыльникова [5], Л.В. Руль [6], И. И. Смотрицкая [7], Ю.Е Хохлов [8] и др. Однако остаются по-прежнему мало изученными особенности формирования цифровой системы предоставления государственных услуг в условиях цифровизации экономики на инновационной основе.

В связи с этим, целью данного исследования является определение сущности и роли цифровизации современного государственного управления в условиях инновационного развития.

Результаты исследования. Переход любого государства к информационному обществу требует переосмысления, а в отдельных случаях и 
разработки новых механизмов регулирования отношений, возникающих между гражданами, их объединениями и государством. Bce субъекты информационных отношений должны осознавать и выполнять свою роль в этом процессе, но именно государство предназначено активно влиять на качественную сторону трансформационных процессов, привлекать к сотрудничеству политиков, ученых, практиков, общественность.

Данный факт демонстрирует теория Кондратьева, которая изучает циклы развития экономики в мире.

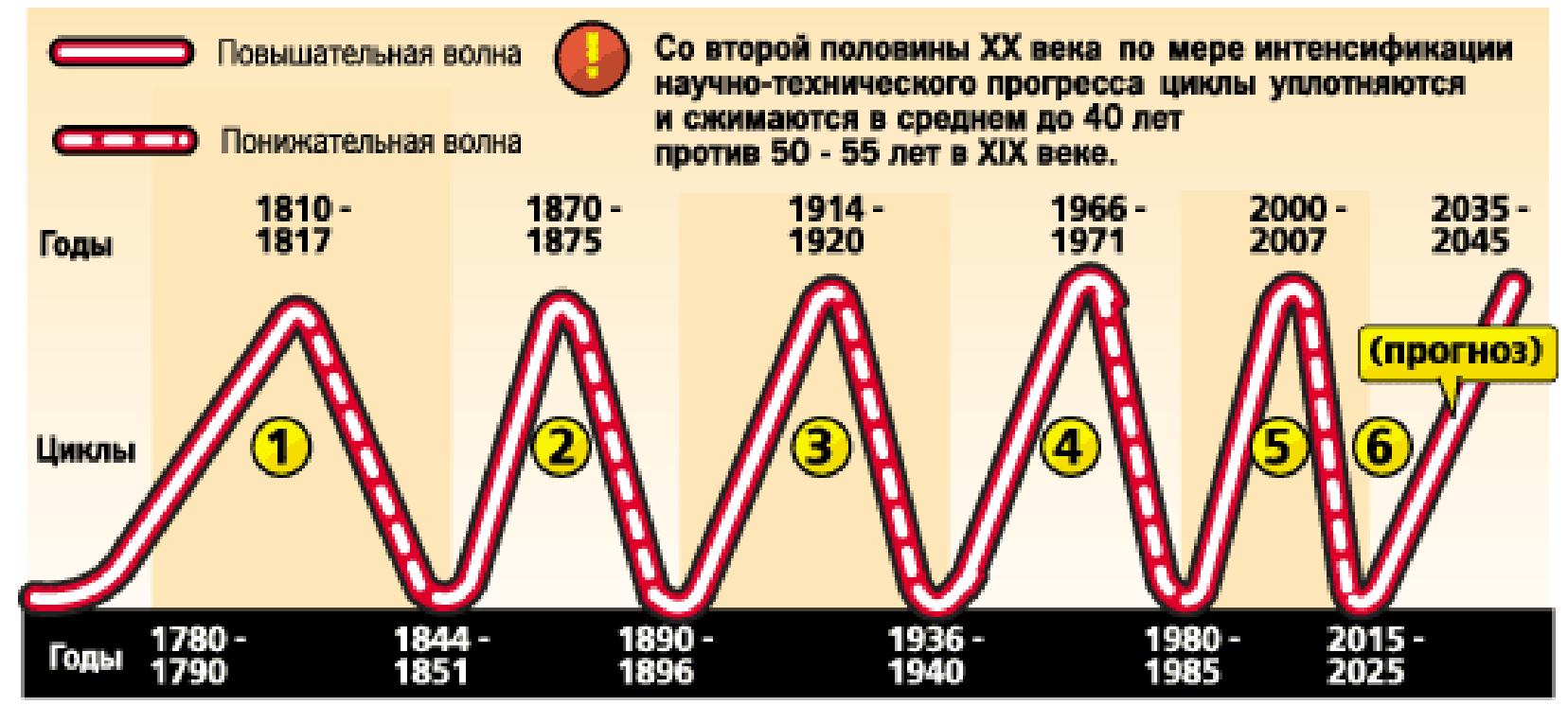

Рис. 1 Циклы Кондратьева в развитии мировой экономики [1]

Наличие корреляции между уровнем развития инновационной деятельности в стране и уровнем экономического развития подтверждается при изучении динамики соотношения доходной и расходной части федерального бюджета РФ (рис. 2).

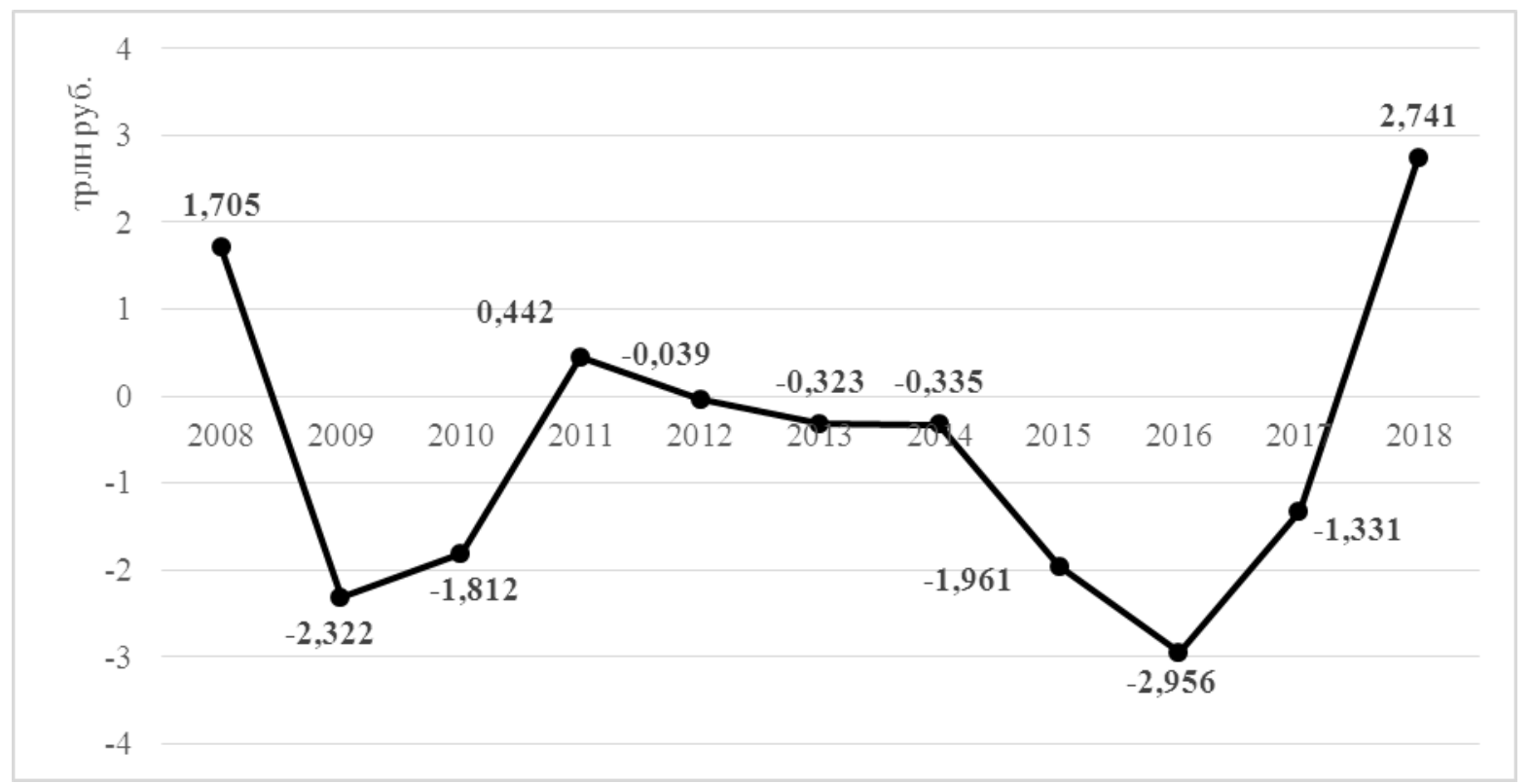

Рис. 2 Динамика сальдо федерального бюджета РФ ( построено на основе данных [4]) 
Поскольку российская экономика является ресурсо-ориентированной, в 2008-2009 гг. появился дефицит бюджетных средств (это годы мирового кризиса). В 2016 г. дефицит объясняется воздействием кризисных явлений, вызванных введенными санкциями. В 2018 г. достигается положительное сальдо, что связывается с изменением курса зависимости национального хозяйства от экспорта ресурсов, переориентируясь на повышение роли инновационного развития и внедрение импортозамещения. Подобные тенденции соответствуют динамике, предложенной в теории Кондратьева.

В результате можно утверждать о необходимости применения цифровых технологий в государственном управлении, которые являются основой современного динамичного развития большинства стран.

Содержание информационного общества - повышенное внимание к знаниям, которыми располагает общество и потенциалу их развития. Содержание же управления в публичном секторе - поиск наилучших способов использования всех ресурсов, в том числе и интеллектуальных, для достижения приоритетных целей государства.

В последнее десятилетие происходит трансформация государственного управления в направлении его приспособления к требованиям информационного общества и информационной эры. На основе информационных технологий ускоряется процесс принятия решений и их воплощение, высвобождается часть рабочего времени; появляется механизм эффективного консультирования общественности о проведении государственной политики, определяются новые каналы предоставления гражданам информации и услуг; этот процесс проявляется в изменении подходов к механизмам управления и постепенной переориентации базовых принципов с акцентом на обеспечение широкого участия граждан в обсуждении и принятии государственных решений [5].

Основными направлениями общественных потребностей и запросов субъектов электронного управления, которые формируют его объект, являются:

- создание, отправка, передача, получения, обработка, использование, контроль выполнения и хранения электронных документов;

- технологическое объединение функционально связанных составляющих системы электронного взаимодействия и комплексная система защиты информации;

- доступ и обеспечение с помощью средств информационнокоммуникационных технологий к загрузке, заполнению, представлению в электронной форме заявлений и других документов, обращение к дистанционной оплате за предоставление государственной услуги, в электронной форме, а также получение субъектами обращения информации о ходе рассмотрения их заявлений и результатов предоставления административных услуг;

- непосредственное удовлетворение потребностей и запросов физических и юридических лиц в сфере финансов (налоги, страхование, финансовые услуги), социальной защиты (пенсионное, социальное 
обеспечение), регистрации (физических лиц-предпринимателей, юридических лиц и т.п.), нотариальной деятельности, гражданства и миграции, образования и культуры, семьи, безопасности и защиты, связи и информатизации, внешнеэкономической деятельности, недвижимого имущества и строительства, сельского хозяйства, природных ресурсов и экологии, транспорта, интеллектуальной собственности [3].

Процесс предоставления электронных услуг должен осуществляться следующим образом:

1) происходит подготовка и размещение информации о публичной услуге соответствующим органом публичной администрации на официальном вебсайте и / или в Едином государственном портале административных услуг;

2) осуществляется информирование физических и юридических лиц о порядке предоставления публичных услуг;

3) обеспечивается прием, и регистрация электронного заявления от лица о получении публичной услуги с использованием информационнокоммуникационных технологий:

4) происходит передача принятого электронного заявления лица к ведомственным информационным ресурсам с использованием информационнокоммуникационных технологий:

5) завершается предоставление электронной услуги путем получения лицом электронного документа или его получения в бумажном виде в установленное в электронной очереди время [2].

По мере нарастания уровня зрелости в процессе трансформации формируются ключевые принципы цифрового правительства:

- приверженность принципу «цифровой от начала до конца» (digitalendto-end);

- проектирование клиенто-центрических услуг;

- платформонезависимость внедряемых услуг;

- реализация стратегии, основанной на использовании данных;

- содействие использованию открытых данных;

- открытость для инноваций и «подрывных» технологий.

Цифровизация государственного управления предполагает следующие направления:

- развитие электронного правительства;

- повышение качества государственного управления за счет создания и внедрения современных информационных технологий;

- оказание услуг на базе информационных технологий в области медицины, здравоохранения и социального обеспечения;

- развитие сервисов на основе информационных технологий в области образования, науки и культуры;

- поддержка региональных проектов в сфере информационных технологий [7]. 
На современном этапе информатизация общества распространилась на все сферы жизни граждан ДНР, в том числе и на органы власти. Объем и особенности информационных технологий Республики, уровень их применения определяют уровень развития молодой страны и ее статус в мире. Исследование показало, что количество и качество информатизации государственной власти ДНР находится пока на недостаточном уровне. Для государственного управления ДНР приоритетным должно быть совершенствование степени информатизации всех межотраслевых систем и их качественное взаимодействие.

На данном этапе система «Электронное правительство» в Донецкой Народной Республике находится на начальном этапе формирования. Для успешного воплощения электронного управления как идеи и обеспечения полной реализации всех преимуществ нашей стране, безусловно, необходимо осуществить приближение системы государственного управления к российским стандартам. Для этого молодой республике необходимо определенное время, поскольку окончательный переход $к$ электронному управлению требует прохождения множества промежуточных этапов от декларирования на высшем государственном уровне этого направления в качестве приоритетного к совершенствованию системы подготовки, переподготовки и повышению квалификации государственных служащих, которые будут непосредственно осуществлять соответствующие функциональные обязанности.

Проанализировав причины достаточно низкой эффективности (по сравнению с другими странами) применения цифровых технологий в государственном управлении, можно сделать вывод, что основными проблемами являются:

- формальный подход, консерватизм и бюрократизм госслужащих;

- низкая активность самих граждан в данном вопросе;

- отсутствие четкого целеориентирования;

- отсутствие концептуального, системного подхода, что приводит к путанице и несогласованности в нормативно-правовой базе, технической и организационной нагроможденности.

В обобщенном виде можно определить следующие этапы преодоления создавшихся сложностей и создания электронной системы государственных услуг в Республике:

I этап: обеспечение возможности удаленного доступа субъекта обращения к полной, актуальной и достоверной информации об административной услуге;

II этап: обеспечение возможности удаленного доступа субъекта обращения для загрузки, заполнения и печати электронных заявлений и других документов, необходимых для получения услуги, с помощью информационнокоммуникационных технологий. На этом этапе субъекты обращения имеют возможность заранее сформировать необходимый пакет документов для последующего обращения к соответствующему субъекту предоставления услуги; 
III этап: обеспечение дистанционных консультаций субъектов обращения субъектами предоставления услуги, удаленная запись на прием к субъекту предоставления услуги.

Реализация последующих этапов перевода административных услуг в электронную форму будет возможна при условии нормативно-правового, организационного и технологического обеспечения этого процесса на высших уровнях публичного управления в связи с необходимостью:

- реализации электронной идентификации и аутентификации субъекта обращения при подаче заявления и документов, необходимых для получения услуги, в электронной форме;

- формирования и передачи электронных документов от субъекта обращения в соответствующий орган управления;

- определение электронных форм заявлений и иных документов, необходимых для получения услуги;

- разработки и утверждения информационных и технологических карт услуг.

В связи с этим в работе выделены основные перспективные направления развития цифровых технологий в государственном управлении, которые приведены и обоснованы ниже.

1. По примеру давно созданного информационного ресурса в Российской Федерации для получения желаемой оптимизации цифровых технологийнеобходимо создание единого портала государственных услуг, который уже на данном этапе и в перспективе развития Республики позволит улучшить эффективность информатизации нашего общества. Данный ресурс позволит обеспечить информационно-технологическое взаимодействие всех информационных систем, предоставляющих государственные услуги в электронном виде.

2. Социальные сети. Перспектива использования социальных сетей в государственном управлении очевидна. На данный момент в республике социальные сети не являются полноценным ресурсом для управленческой деятельности, отсутствует возможность оставлять свой электронный адрес в качестве официального. Так, в Законе ДНР «Об обращениях граждан» обращение на официальном уровне предусмотрено только в письменном или устном формате, но не в электронном. А в законодательстве РФ при электронном обращении официально указывается адрес электронной почты, куда необходимо отправить ответ. Поэтому такое использование цифровых технологий в деятельности органов власти ДНР является также перспективным направлением, которое нуждается в методическом и правовом обеспечении.

3. Динамичное развитие цифровых технологий в нашей республике позволяет в перспективе создать систему «Электронное правительство» по аналогичному типу и опыту внедрения в Российской Федерации. Здесь применим такой способ предоставления электронных государственных услуг гражданам, бизнесу и другим органам власти, при котором «максимально 
применимы информационные технологии для минимизации личного взаимодействия» [6].

4. Внедрение современного программного обеспечения по работе с обращениями граждан во всех ведомствах - перспективное направление информатизации управления ДНР. На данном этапе вне зависимости от способа обращения вседанные граждан регистрируются в информационной базе «Обращения граждан» отделом по работе с обращениями граждан Донецкой Народной Республики.

Перспективы развития автоматизированной информационной системы (АИС) «Обращения граждан» заключаются в применении мобильного приложения для Android и IOS; установка терминалов для подачи обращений в общественных местах; SMS-рассылки для извещения граждан о ходе рассмотрения обращений; введение системы нематериальных поощрений для сотрудников.

Таким образом, как показали результаты проведенного исследования, усовершенствование АИС «Обращения граждан» путем информатизации государственного управления и внедрения единого программного обеспечения в структурных подразделениях администраций Донецкой Народной Республики принесет значительную оптимизацию как экономического эффекта, так и процессуального.

5. Применение информатизационно-управляющих систем для решения задач прогнозирования, реагирования и предупреждения кризисных и других внештатных ситуаций - одно из перспективных направлений информатизации органов власти в качестве стратегического и оперативного управления для решения актуального комплекса проблем ДНР через увеличение уровня прозрачности государственных слуг; наращивание эффективности государственного управления на всех уровнях власти; предотвращение коррупции; создание альтернативных каналов коммуникации для общества и государства; рост уровня гражданского доверия к власти.

В данном контексте к наиболее перспективным направлениям цифровизации государственного управления можно отнести: информационноуправленческие, локальные вычислительные сети, интернет-технологии.

6. Учитывая возросшую роль информации, интернета, телекоммуникаций, одним из приоритетов в развитии цифровых технологий в государственном управлении является безопасности в сфере информационных угроз. Для этого необходимо:

- усовершенствовать безопасность информационных систем, включая безопасность телекоммуникационных сетей (прежде всего безопасность первичных телекоммуникационных сетей и информационных систем органов государственной власти, систем и средств связи вооруженных сил);

- способствовать развитию отечественного производства средств информатизации, телекоммуникации и связи, информационных продуктов.

- обеспечить защиту сведений, составляющих государственную тайну.

Выводы. Таким образом, направление развития цифровых технологий в государственном управлении ДНР является одним из перспективных. 
Основные пути внедрения подобной системы в государственное управление следующие: создание единого портала государственных услуг; расширение использования социальных сетей; планомерное, поэтапное внедрение системы «Электронное правительство».

Формируемые потоки информации становятся все более востребованными для уверенного функционирования государственной власти и для всего общества в целом. Поэтому рассмотренные перспективы применения цифровых технологий в государственном управлении нашей страны должны способствовать качественному взаимодействию управляемой и управляющей систем.

Перспективами дальнейших исследований является анализ возможности имплементации зарубежного опыта формирования эффективной инновационной системы в государственном управлении посредством использования элементов цифровой экономики в отечественной практике.

\section{Список литературы}

1. Автор теории длинных волн экономической конъюнктуры. Теория длинных волн / Opsar.ru [Электронный pecypc]. - Режим доступа: https://opsar.ru/biznes-idei/avtor-teorii-dlinnyh-voln-ekonomicheskoi-konyunkturyteoriya-dlinnyh-voln-teoriya.html.

2. Громов, И.А. Влияние цифровых технологий на сферу государственных и бизнес-услуг в России / И.А. Громов // Проблемы современной экономики. - 2018. - № 3 (67). -С. 43-47.

3. Костин, К.Б. Современные технологии цифровой экономики как драйвер роста мирового рынка товаров и услуг / К.Б. Костин, А. А. Березовская // Экономические отношения. - 2019. - Т. 9 - № 2. - С. 455-480.

4. Краткая информация об исполнении федерального бюджета / Официальный сайт Минфина России [Электронный ресурс]. - Режим доступа: https://www.minfin.ru/ru/statistics/fedbud/execute/?id_65=80041yezhegodnaya_informatsiya_ob_ispolnenii_federalnogo_byudzhetadannye_s_1_yanv arya_2006_g.

5. Мыльникова, Л.А. Инновации и цифровизация российской экономики / Л.А. Мыльникова // Экономический журнал. - 2019. - № 1 (53). - С. 107-119.

6. Руль, Л.В. Интернет-порталы как элемент технологии в государственном и муниципальном управлении / Л.В. Руль // Научные исследования и разработки студентов: материалы Междунар. студенч. науч.практ. конф. (Чебоксары, 5 сент. 2016 г.). - 2016. - С. 114-117.

7. Смотрицкая, И.И. Современные тенденции цифровой трансформации государственного управления / И.И. Смотрицкая, С.И. Черных // Вестник Института экономики РАН. - 2018. - № 5. - С. 22-36.

8. Хохлов, Ю.Е. Глобальный передовой опыт для цифровой трансформации государственного сектора в России / Ю.Е. Хохлов // Конкуренция в цифровую эпоху: Стратегические вызовы для Российской Федерации, Publisher: Всемирный банк, 2018. - С. 50-65. 